\title{
Alterações Morfométricas em Músculo Respiratório de Ratos Submetidos à Imobilização de Pata
}

\section{Morphometric Alterations in Respiratory Muscle of Rats Submitted to Paw Immobilization}

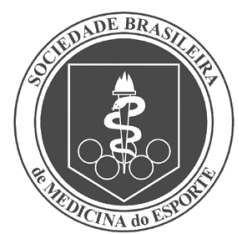

Artigo Original

\author{
Francisco Fleury Uchôa Santos- \\ Júnior ${ }^{1}$ \\ Jamille Soares Moreira Alves² \\ André Accioly Nogueira Machado' \\ Patrick Simão Carlos ${ }^{2}$ \\ Alex Soares Marreiros Ferraz' \\ Roseli Barbosa² \\ José Henrique Leal-Cardoso \\ Vânia Marilande Ceccatto ${ }^{1}$
}

1. Mestrado Acadêmico em Ciências Fisiológicas da Universidade

Estadual do Ceará (UECE),

Laboratório de Bioquímica e Cultura

de Células (LabiCult) - Fortaleza

(CE), Brasil.

2. Mestrado Acadêmico em Ciências Fisiológicas (UECE), Laboratório de Eletrofisiologia (LEF).

Endereço para correspondência: Vânia Marilande Ceccatto,

Laboratório de Bioquímica e Cultura de Células (LabiCult) - Mestrado Acadêmico em Ciências Fisiológicas. Av. Paranjana, 1.700 - Campus do Itaperi - 60740-000 - Fortaleza (CE), Brasil. (www.uece.br/cmacf).

E-mail: ceccatto@uece.br

\begin{abstract}
RESUMO
A imobilização é um recurso frequentemente utilizado na prática clínica, sendo comum em patologias álgicas e nas fraturas. O objetivo deste estudo foi analisar a influência do processo de imobilização em músculo do sistema respiratório, o diafragma. O experimento foi efetuado com 12 ratos Wistar machos divididos em dois grupos, controle e imobilizado. O procedimento de imobilização foi realizado através de um método alternativo de imobilização por fita adesiva, sendo mantida por duas semanas. Analisouse a morfometria das fibras do diafragma com coloração de hematoxilina e eosina. Ao compararmos o diâmetro médio das fibras musculares do diafragma dos animais imobilizados $(47,15 \mu \mathrm{m} \pm 0,329 \mu \mathrm{m}) \mathrm{em}$ relação ao controle $(54,67 \mu \mathrm{m} \pm 0,396 \mu \mathrm{m})$, encontramos diferença estatística entre os grupos ( $p<0,0001)$. Considerando os dados encontrados, foi possível concluir que a imobilização de pata, no modelo utilizado, foi capaz de gerar hipotrofia da musculatura respiratória, assim como um quadro geral de redução de massa corporal do animal.
\end{abstract}

Palavras-chave: hipocinesia, diafragma, histologia.

\begin{abstract}
Immobilization is a frequently used procedure in clinical practice and common in pain diseases and fractures. This study examined the influence of immobilization in a muscle-related respiratory system, the diaphragm. This experiment was conducted with twelve male rats divided into two groups, control and immobilized with an alternative method of restraining by tape, kept for two weeks. We analyzed the morphometry of the diaphragm muscle fibers with hematoxylin/eosin staining. Statistical difference was found $(p<0.0001)$ when the average diameter of the diaphragm muscle fibers of immobilized animals $(47.15 \mu \mathrm{m} \pm 0.329 \mu \mathrm{m})$ was compared to the ones in the control group $(54.67 \mu \mathrm{m} \pm 0.396 \mu \mathrm{m})$. Considering the results, it can be concluded that the immobilization of the animal paw in the used model was able to produce hypotrophy of respiratory musculature, as well as a general framework for reducing the mass of the animal.
\end{abstract}

Keywords: hypokinesia, diaphragm, histology.

\section{INTRODUÇÃO}

A imobilização é um recurso frequentemente utilizado na prática clínica, sendo comum em patologias álgicas e nas fraturas. Entretanto, o seu entendimento fisiológico ainda necessita ser buscado. Sabe-se que mesmo pequenos períodos acarretam diversos prejuízos à região imobilizada, especialmente a condição de hipotrofia/atrofia muscular ${ }^{(1)}$. Outra questão importante é que a imobilização causa transtornos em outras partes do organismo, interferindo inclusive no metabolismo ${ }^{(2-4)}$.

O processo de atrofia muscular envolve alterações metabólicas, bioquímicas e estruturais que afetam a funcionalidade dos músculos envolvidos. A estrutura e a função dos músculos esqueléticos são condicionadas pela atividade proprioceptiva, pela inervação motora, pela carga mecânica imposta ao tecido, pela realização de ciclos de estiramento/encurtamento e pela mobilidade das articulações. O comprometimento de algum desses fatores certamente acarretará um quadro de hipotrofia ou atrofia muscular ${ }^{(5)}$.
O tecido muscular é caracterizado por realizar contrações (ciclos de estiramento/encurtamento) e essa atividade contrátil parece ser determinante na massa muscular e pode preceder os sinais endócrinos para a depleção de proteínas no músculo. Além disso, os músculos mantidos inativos são mais sensíveis aos sinais catabólicos dos hormônios contrarregulatórios ${ }^{(6,7)}$, favorecendo a perda em relação ao ganho proteico e de massa muscular, consequentemente. Estudos com músculos isolados mostram que a taxa de transporte de aminoácidos está diretamente ligada à atividade contráti|(6,8), logo, menor atividade contrátil, como o que acontece durante um processo de imobilização, estará relacionada a um menor transporte de aminoácidos.

A perda de massa muscular associada à perda de força é uma das primeiras e mais óbvias modificações que ocorrem como resultado da imobilização. Essa perda é mais acentuada nas primeiras 72 horas, com índices de 14 a 17\%, reduzindo sua velocidade após uma semana de imobilização ${ }^{(9-11)}$. Além de ocorrer um aumento na perda de força 
muscular, existe ainda outro fator relevante no processo: a velocidade de síntese proteica, que começa a declinar seis horas após o início da imobilização(10).

Observa-se ainda que o acúmulo do tempo de imobilização gera ainda mais prejuízos à saúde do paciente, de modo que três semanas de imobilização resultam em perda de $47 \%$ da força muscular ${ }^{(12)}$. Esse processo de hipotrofia/atrofia da musculatura esquelética, resultante da ausência de cargas, é uma das maiores mudanças associadas com o descondicionamento físico, interferindo inclusive em atividades de rotina do paciente ${ }^{(13)}$.

Atualmente, ao induzir atrofia muscular que se aproxime das condições de restrição ao leito e hipoatividade, dois modelos são considerados os mais apropriados: a suspensão e a imobilização. Em estudo comparativo, os dois modelos produzem reduções significativas na massa do músculo sóleo, duração da contração isométrica e pico de tensão tetânica ${ }^{(14)}$. As técnicas de inervação, transecção de raiz neural ou medular, tenotomia, fixação das articulações com pinos e castração, utilizadas para mimetizar a hipoatividade, apresentam particularidades que podem alterar os índices de atrofia quando comparados aos dois previamente citados ${ }^{(15,16)}$.

A imobilização gessada permite a integridade dos nervos, músculos e tendões. Não é invasiva e evita a descarga sobre os membros imobilizados, facilitando o estudo dos efeitos da diminuição do trabalho muscular, além de ser um procedimento próximo às condições que vivenciamos na prática clínica e permitindo mais facilmente o estudo dos acontecimentos decorrentes deste processo ${ }^{(15,16)}$. Entretanto, na sua utilização em modelos animais, algumas dificuldades podem ser encontradas. Uma das mais frequentes é o edema de pata do membro imobilizado, por redução da vascularização local, quer seja pelo apareIho gessado como um todo, quer seja por um único fio do gesso que tenha um pouco mais de pressão. Quando aplicada pouca pressão para reduzir essa problemática, o animal pode, simplesmente, escapar do aparelho gessado, já que o mesmo possui alta capacidade de movimentação corporal, facilitando sua passagem por locais de tamanho fixo e estreito.

Para solucionar esse empecilho, foi proposto, de forma inédita, a utilização de um método alternativo de imobilização, utilizando fita adesiva ao invés de gesso, no sentido de promover a fixação do aparato ao animal e de manter a imobilização durante todo o experimento.

A plasticidade funcional muscular é a capacidade de se adaptar a um determinado estímulo, como a imobilização e o exercício físico. Esta propriedade ocorre tanto em músculos periféricos, ligados ao sistema locomotor, como em outros relacionados com os demais sistemas do corpo, como o diafragma, importante músculo ligado ao sistema respiratório. Este também pode passar por um estado de inatividade, como observado nos casos de ventilação mecânica, gerando hipotrofia e, inclusive, progredir para a atrofia ${ }^{(17)}$. Entretanto, pouco se conhece sobre a sua condição, quando da ocorrência da imobilização de um membro. Neste sentido, o objetivo deste estudo foi analisar a influência do processo de imobilização em um músculo relacionado ao sistema respiratório, o diafragma.

\section{MÉTODOS}

A pesquisa foi aprovada pelo Comitê de Ética para o Uso de Animais (CEUA) da UECE, sob o no 08351785-5 de 26/08/2008. Foram utilizados 12 ratos (Rattus norvegicus, Wistar) machos, adultos-jovens (oito semanas de idade), com peso corporal médio de $300 \mathrm{~g} \pm 15 \mathrm{~g}$ provenientes do Biotério da Universidade Estadual do Ceará (UECE), sob temperatura de $22^{\circ} \mathrm{C}$ a $25^{\circ} \mathrm{C}$ com ciclo de 12 horas claro e 12 horas escuro, recebendo ração e água ad libitum.
Os animais foram distribuídos em dois grupos de seis animais cada. Grupo controle (GC): seis animais no início do experimento foram separados dos demais, pesados e deixados nas gaiolas por duas semanas e depois sacrificados. Grupo imobilizado (Gl): seis animais com as mesmas características do grupo controle, sendo o membro posterior direito imobilizado durante duas semanas e sacrificados em seguida.

Previamente, os animais foram anestesiados com cetamina 60mg/ $\mathrm{kg}$ e xilasina $8 \mathrm{mg} / \mathrm{kg}$ de peso do animal. A imobilização do membro posterior direito foi efetuado da seguinte forma (figura 1A): utilizouse esparadrapo impermeável (marca $\mathrm{Cremer}^{\circledR} \mathrm{com} 10 \mathrm{~cm}$ de largura), que incluiu a pelve, quadril, joelho (ambos em extensão) e tornozelo (em flexão plantar). Foram colocadas ataduras de algodão com quatro centímetros de largura nas articulações para prevenir a formação de úlceras de pressão. Em seguida, a pata direita dos animais foi enfaixada com as tiras de esparadrapo, de cinco centímetros de largura e $15 \mathrm{~cm}$ de comprimento cada. Para deixar a pata enfaixada firme, foi feita a fixação da mesma no tronco com um enfaixamento na pelve do animal, da mesma forma. As tiras foram substituídas ou reforçadas, quando danificadas e mantidas por duas semanas.

Os animais, já divididos em seus respectivos grupos, foram colocados em gaiolas convencionais plásticas (três animais em cada) com livre acesso à ração e água. A imobilização não impediu a locomoção dentro da gaiola, assim como o acesso à água e à ração, conforme apresentamos em Resultados.

Ao fim do tratamento os animais foram anestesiados com cetamina $60 \mathrm{mg} / \mathrm{kg}$ e xilasina $8 \mathrm{mg} / \mathrm{kg}$ de peso do animal. Em seguida, sacrificados por decapitação, de acordo com a resolução do Conselho Federal de Medicina Veterinária - CFMV/CRMVs - n 714, 20/06/2002, para posterior dissecação do diafragma e da tíbia.

Após o sacrifício e dissecação, o diafragma foi pesado. Para normalização dos dados, o peso do diafragma foi dividido pelo comprimento da tíbia ${ }^{(18)}$. Em seguida o músculo foi processado para os estudos morfométricos. A metodologia baseou-se em Ross e Reith ${ }^{(19)}$ modificado.

O estudo do diâmetro médio de fibras musculares esqueléticas analisou três cortes transversais do diafragma de cada animal, fora do centro tendíneo. Em cada corte, duas áreas, com raio de 1.000 um, foram aleatoriamente selecionadas, apresentando a fibra corada em corte transversal. Dentro desta área foram identificadas 50 fibras (figura 1B). No total, mediu-se o diâmetro (em um) de 1.800 fibras para cada grupo. O equipamento incluiu um microscópio "Zeiss Primo Star", conectado a uma câmera Pixelink modelo PLA 662, com objetiva 4 × 0,10 para analisar o diâmetro de fibras do músculo. Para as medidas utilizou-se o software Axiovision 3.1.2.1 (Zeiss ${ }^{\oplus}$ ). Todas as análises foram feitas por um único avaliador, na Universidade de Fortaleza - UNIFOR - Fortaleza - CE.

Para a análise estatística foi utilizado o Teste $t$ de Student para amostras independentes e a significância estatística foi considerada para $p<0,05$, sendo utilizado o software estatístico GraphPad Prism 5.0 como ferramenta para análise estatística.

\section{RESULTADOS}

Os resultados deste estudo mostram redução do peso dos animais imobilizados $(297,3 \mathrm{~g} \pm 14,55 \mathrm{~g})$ em relação ao controle $(370,3 \mathrm{~g} \pm 7,23 \mathrm{~g})$ no dia do sacrifício ( $p<0,05)$, conforme figura 2A. Os animais apresentaram também redução do peso normalizado do diafragma do grupo imobilizado $(20,8 \mathrm{mg} / \mathrm{mm} \pm 0,0005 \mathrm{mg} / \mathrm{mm})$, em relação ao controle $(26,3 \mathrm{mg} / \mathrm{mm} \pm 0,0016 \mathrm{mg} / \mathrm{mm})$, $(p<0,05)$, conforme figura $2 B$.

Comparando o diâmetro médio das fibras musculares do diafragma dos animais imobilizados $(47,15 \mu \mathrm{m} \pm 0,329 \mu \mathrm{m})$ em relação ao controle $(54,67 \mu \mathrm{m} \pm 0,396 \mu \mathrm{m})$, ocorreu diferença significativa entre os grupos ( $p<0,0001)$, conforme figura 2 . 

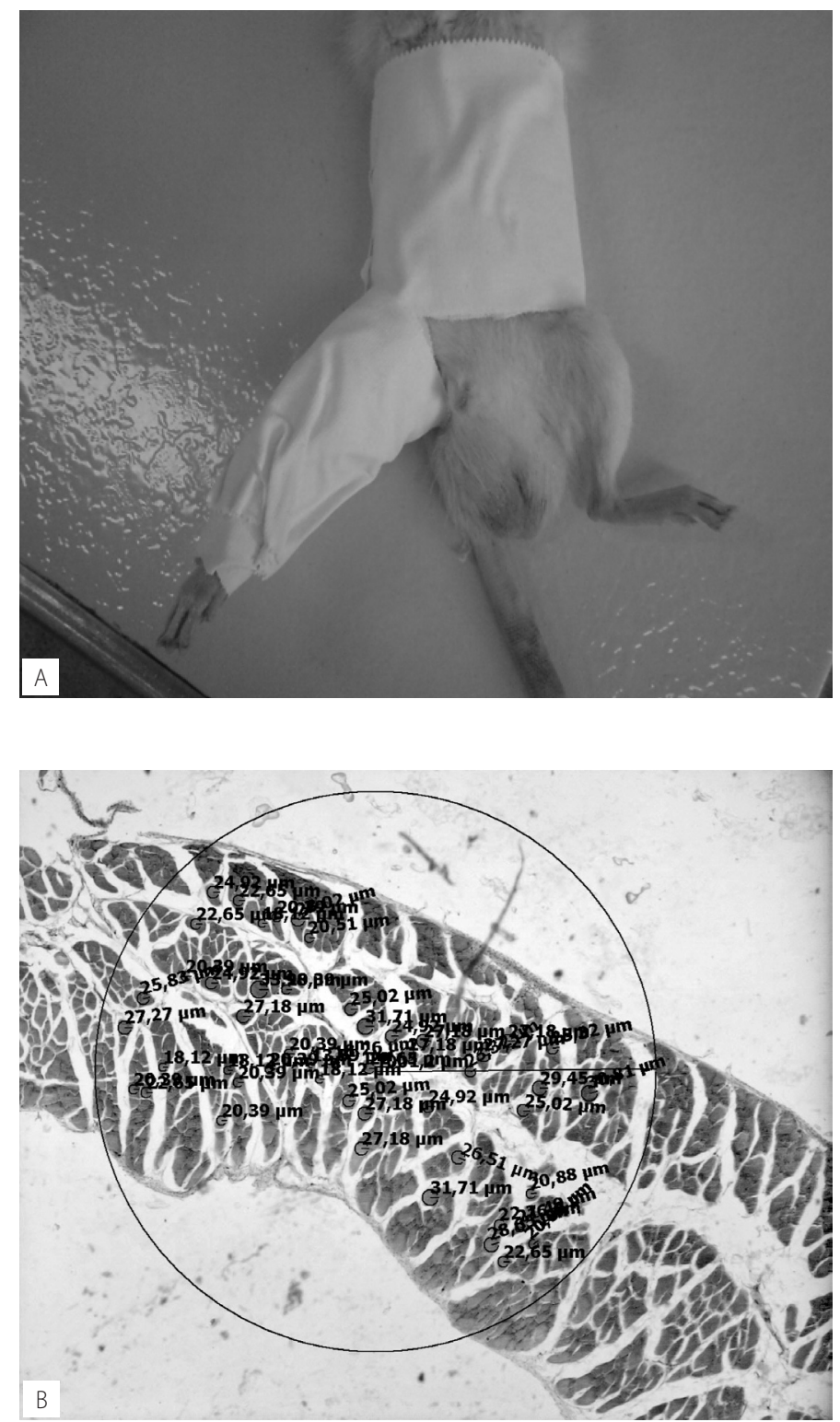

Figura 1. A) Modelo de imobilização utilizado. B) Lâmina histológica do diafragma na análise do diâmetro de fibras.

Com relação ao uso de esparadrapo, ao invés de gesso, obteve-se os seguintes benefícios: sem alterações na mobilidade do animal, possibilitando normalidade na alimentação e outras funções vitais, ausência de úlcera de pressão ou edema de pata e total retenção do sistema de imobilização durante o tempo proposto. Entretanto, torna-se crítica a revisão diária devido às mordidas.

\section{DISCUSSÃO}

Durante um processo de imobilização já se sabe que existe atrofia da musculatura esquelética do membro imobilizado. E que, além disso, o próprio indivíduo sofre perdas em diversos segmentos e sistemas de seu organismo ${ }^{(20)}$, como transtornos de inervação, circulação, atrofia óssea, alterações ligamentares, aumento de tecido conjuntivo, edema, rigidez articular, alterações morfométricas e histológicas das fibras musculares ${ }^{(21)}$.

O diafragma possui características próprias em sua funcionalidade, já que ele é um músculo esquelético e, portanto, voluntário. Recebendo ainda a influência direta do centro respiratório na medula oblonga no sentido de realizar uma contração muscular, o que gera uma diferença de pressão torácica e, consequentemente, a respiração. Ou seja, não é possível se obter um controle voluntário total sobre esse músculo.
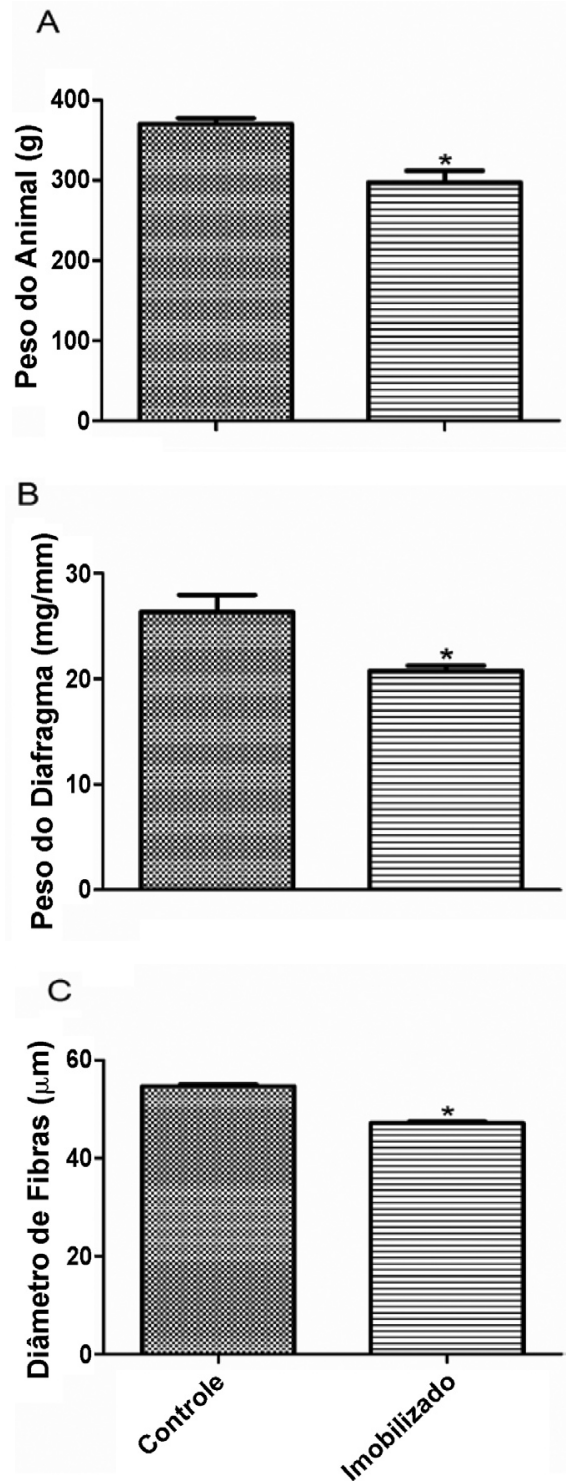

Figura 2. A) Representação gráfica do peso dos animais dos dois grupos $(p<0,05)$. B) Representação gráfica do peso do diafragma normalizado pelo comprimento da tíbia ( $p<0,05$ ). C) Representação gráfica do diâmetro de fibras musculares entre o diafragma do GC e do $\mathrm{Gl}(\mathrm{p}<0,0001)$. Foi utilizado para análise estatística o teste $t$ para amostras independentes com nível de significância $p<0,05$.

Os resultados mostraram redução do diâmetro das fibras musculares do diafragma (figura $2 \mathrm{C}$ ) associado a redução do peso deste mesmo músculo (figura 2B), indicando que houve perda de tecido muscular, o que condiz com achados de diferentes pesquisadores em relação ao músculo esquelético submetidos à imobilização. A atrofia muscular caracteriza-se pela diminuição do tamanho da fibra muscular(9-11,22), área de secção transversal e conteúdo proteico ${ }^{(10,22)}$, redução da potência muscular, maior fatigabilidade e aumento da resistência à insulina (22). Sabe-se que a diminuição da síntese e o aumento da degradação proteica envolvidas neste processo contribuem para a perda total de proteína muscular devido ao desuso. Embora os acionadores que causam atrofia sejam diferentes, a perda de massa muscular, em cada caso, envolve uma via comum que estimula a proteólise muscular. Baseado no conhecimento atual da atrofia muscular por um período de imobilização, considera-se que o mesmo é um processo que envolve a interação entre duas ou mais vias de sinalização, ao invés da ideia de se trabalhar com uma via isolada como responsável(22). 
Essa situação correlacionar-se-ia com a redução no tamanho do músculo e queda na tensão por unidade de área de secção transversal do músculo(9-11). Outras duas situações em relação à imobilização, vistas no modelo de suspensão do membro realizado no trabalho de Guillot et al.(3), são as seguintes: a primeira é que a suspensão gerou uma mudança no recrutamento neuronal dos músculos imobilizados, favorecendo flexores em relação a extensores; a outra diz que a atrofia muscular está relacionada com o tamanho inicial da fibra, ou seja, músculos com um diâmetro maior de suas fibras apresentam atrofia mais expressiva em relação aos músculos com menor diâmetro.

Do mesmo modo que os tecidos do nosso organismo respondem a uma situação de estresse mecânico, modificando suas propriedades, a ausência total de movimento, que também pode ser considerada um estresse, também produz readaptações nessas estruturas. De um modo geral, a perda de componentes básicos do tecido em virtude de um processo de imobilização pode repercutir negativamente nas funções teciduais básicas'(23).

Além da redução do diâmetro de fibras musculares e do peso do diafragma, ocorreu ainda redução do peso do animal, corroborando com o estudo de Konno et al.(24), onde foi observada a redução da área de secção transversa e da massa muscular; entretanto, isto ocorreu em um músculo do sistema locomotor, o sóleo, provavelmente por redução na síntese proteica. No estudo apresentado, devemos lembrar que as situações que expõem o diafragma a um quadro de hipotrofia/ atrofia muscular por desuso dizem respeito à permanência em uso de ventilação mecânica ${ }^{(17)}$. Desta forma, comprova-se a capacidade do sistema respiratório de sofrer influência em sua musculatura, o que corrobora com os dados apresentados, em relação ao modelo de imobilização proposto, no sentido de gerar um quadro de hipotrofia do diafragma.

\section{CONCLUSÃO}

Considerando os dados encontrados, foi possível concluir que a imobilização de pata, no modelo utilizado com esparadrapo, mostrouse mais segura para o animal, além de fácil manutenção. Principalmente, foi capaz de gerar hipotrofia da musculatura respiratória, assim como um quadro geral de redução de massa corporal do animal. Desta forma, é provável que surjam comprometimentos respiratórios nos pacientes imobilizados. Certamente, cabe ao fisioterapeuta estar alerta à esta possibilidade, analisando então a inclusão ou não, em seu trabalho, de ações para os músculos respiratórios.

\section{APOIO FINANCEIRO}

Capes (Coordenação de Aperfeiçoamento de Pessoal de Nível Superior), Funcap (Fundação Cearense de Apoio ao Desenvolvimento Científico e Tecnológico), Conselho Nacional de Desenvolvimento Científico e Tecnológico (CNPq).

Todos os autores declararam não haver qualquer potencial conflito de interesses referente a este artigo.

\section{REFERÊNCIAS}

1. Caierão QM, Teodori RM, Minamoto VB. A influência da imobilização sobre o tecido conjuntivo muscular: uma revisão. Fisioterapia em Movimento 2007;20:87-92.

2. Appell HJ. Muscular atrophy following immobilization: a review. J Sports Med 1990;10:42-58.

3. Coutinho EL, Gomes ARS, França CN, Oishi J, Salvini TF. Effect of passive stretching on the immobilized soleus muscle fiber morphology. Braz J Med Biol Res 2004;37:1853-61.

4. Williams PE, Goldspink G. Connective tissue changes in immobilized muscle. J Anat 1984;138(Pt 2):343-50.

5. Ferreira R, Neuparth MJ, Ascensão A, Magalhães J, Duarte J, Amado F. Atrofia muscular esquelética. Modelos experimentais, manifestações teciduais e fisiopatologia. Revista Portuguesa de Ciências do Desporto 2004;4:94-111.

6. Goldberg A. Influence of insulin and contractile activity on muscle size and protein balance. Diabetes 1979;28(Suppl 1):18-24.

7. Wasserman $\mathrm{DH}$, Vranic M. Interaction between insulin and counterregulatory hormones in controlo $\mathrm{f}$ substrate utilization in health and diabetes during exercise. Diabetes Metab Rev 1986;1:359-84.

8. Carson JA. The regulation of gene expression in hypertrophing skeletal muscle. Exerc Sport Sci Rev 1997;25:301-20.

9. Booth FW. Effect of immobilization on skeletal muscle. J Appl Physiol 1982;52:1113-8.

10. Falempin M, Mounier Y. Muscle atrophy associated with microgravity in rat: basic data for countermeasures. Acta Astronautica 1998:42:489-502.

11. Machida S, Booth FW. Regrowth of skeletal muscle atrophied from inactivity. Med Sci Sports Exerc 2004;36:52-9.

12. Hortobágyi T, Dempsey L, Fraser D, Zheng D, Hamilton G, Lambert J, et al. Changes in muscle strength, muscle fibre size and myofibrillar gene expression after immobilization and retraining in humans. J Physiol 2000;524:293-304.

13. Norman TL, Bradley-Popovich G, Clovis N, Cutlip RG, Bryner RW. Aerobic exercise as a countermeasure for microgravity-induced bone loss and muscle atrophy in a rat hindlimb suspension model. Aviat Space Environ Med 2000;71:593-8.

14. Rocha MND. Propriedades mecânicas do músculo esquelético de ratas Wistar pós-imobilização e exercício físico em esteira. [Dissertação de Mestrado em Bioengenharia], Universidade de São Paulo, 2006.

15. Booth FW, Kelso JR. Production of rat muscle atrophy by cast fixation. J Appl Physiol 1973;34:404-6.

16. Itai Y, Kariya $Y$, Hoshino $Y$, Morphological changes in rat hindlimb muscle fibers during recovery from disuse athropy. Acta Physiol Scand 2004;181:217-324.

17. Costa $D$, Cancelliero KM, da Silva CA. Perfil bioquímico de ratos durante sessão de estimulação diafragmática elétrica transcutânea. Fisioterapia em Movimento 2006;19:41-9.

18. Aguiar AF. Efeitos do treinamento resistido e da suplementação de creatina sobre a morfologia e a expressão da miosina de cadeia pesada $(\mathrm{MHC})$ no músculo estriado esquelético de ratos Wistar. [Dissertação de Mestrado em Biologia Geral e Aplicada], Universidade Estadual Paulista, 2007.

19. Ross MH, Reith EJ. Histologia: Texto e atlas. 2a. ed. São Paulo: Panamericano, 1993.

20. Dittmier DK, Teasell R. Complications of Immobilization and bed rest. Part 1: Musculoskeletal and cardiovascular complications. Canadian Family Physician 1993;3:1428-37.

21. Carvalho LC, Shimano AC, Picado CHF. Estimulação elétrica neuromuscular e o alongamento passivo manual na recuperação das propriedades mecânicas do músculo gastrocnêmio imobilizado. Acta Ortop Bras 2008;16:161-4.

22. Zhang $\mathrm{P}, \mathrm{Chen} X$, Fan M. Signaling mechanisms involved in disuse muscle atrophy. Med Hypotheses 2007:69:310-21.

23. Aquino CF, Viana SO, Fonseca ST. Comportamento biomecânico e resposta dos tecidos biológicos ao estresse e à imobilização. Fisioterapia em Movimento 2005;18:35-43.

24. Konno EAB, Alves EPB, Bertolini GRF, Barbieri CH, Mazzer N. Remobilização por alongamento estático cíclico em músculo sóleo de ratos imobilizados em encurtamento. Rev Bras Med Esporte 2008:14:122-5. 